\title{
Is it obligatory to donate effectively? Judgments about the wrongness of donating ineffectively
}

\author{
Lucius Caviola (Harvard University) \& Stefan Schubert (Oxford University) \\ Correspondence: lucius.caviola@gmail.com, stefanfredrikschubert@gmail.com
}

\begin{abstract}
Note: this is an early draft containing preliminary studies. Please contact us if you have questions or are interested in working on this research question.
\end{abstract}

\begin{abstract}
Most donations end up with relatively ineffective charities. In this paper, we present five preliminary studies on the hypothesis that people don't find it obligatory to donate effectively. We find that people typically do not find it obligatory to donate to highly effective charities. We explore the conditions under which people $d o$ consider it obligatory to help effectively. For example, we find that people consider effectiveness more important when they are the only person who can help, or when the ineffective option is Pareto dominated by a more effective option. We also find that judgments of how obligatory it is to donate effectively are correlated with judgments of how obligatory it is to donate in the first place.
\end{abstract}

\section{Is it obligatory to donate effectively? Judgments about the wrongness of donating ineffectively}

In this paper, we present five pilot studies that investigate the hypothesis that people don't find it morally obligatory to donate effectively (i.e. to donate to effective charities) when they donate. If true, this could be a part of the explanation of ineffective giving. Presumably people are less motivated to seek out effective charities if they don't find it obligatory to donate effectively. (This is not to say it would be the whole explanation: there are also other causes of ineffective giving, such as misconceptions, biases and preferences for "pet charities". We and others explore them in other projects, e.g. Berman et al., 2018.) Note that this paper has not been peer-reviewed and that the studies were pilots with relatively small sample sizes with room for improvement. We publish them because they could be useful to other researchers. 
The question of whether donating effectively is obligatory or merely supererogatory (i.e. morally good but not obligatory or required) has received significant attention from philosophers (e.g. Parfit, 1984; Pummer, 2016; McMahan, 2018; Woodruff, 2018). Parfit discusses a case where a man is about to lose his arms, and where you can either save one or both arms at great but identical cost to yourself. He argues that in this case, it is not obligatory to intervene, since morality does not demand such strong sacrifices - but if you help, then it would be perverse not to save both arms, given that you could do so at no cost to yourself. In the same vein but in a donation context, Pummer argues that even if it would be supererogatory to give anything at all to charity, it is obligatory to donate effectively once one has decided to give. As far as we know there is no experimental literature on whether lay people share these intuitions.

\section{Studies}

\section{Pilot 1: Charity vs. drowning children}

In our first pilot ( $\mathrm{N}=113$, between subjects design), we had two main aims. First, to test to what extent people find it obligatory to donate effectively (given that you have decided to donate; this phrase omitted henceforth) in a typical charity situation where you are receiving leaflets from different charities in the mail. (See Appendix below for the full vignettes and dependent variables.) Second, to study whether people find it more obligatory to help drowning children effectively. We tested the perceived obligation of these options through asking how wrong participants thought it would be not to choose them. Our results (see Figure 1) were striking: participants found it almost not wrong at all to donate ineffectively in the charity case, whereas they were much more opposed to helping the drowning children ineffectively.

We also asked whether it is wrong not to donate/help at all in these cases. We found two interesting results (see Figure 6, Appendix). First, in both cases, participants found it more wrong to not donate/help at all than to donate/help at all, in contrast to Pummer's view. Second, participants found it more wrong not to help at all in the drowning child condition - and overall, there was a strong correlation between perceived wrongness of donating ineffectively and perceived wrongness of not donating at all, $r=.43, p<.001$. 


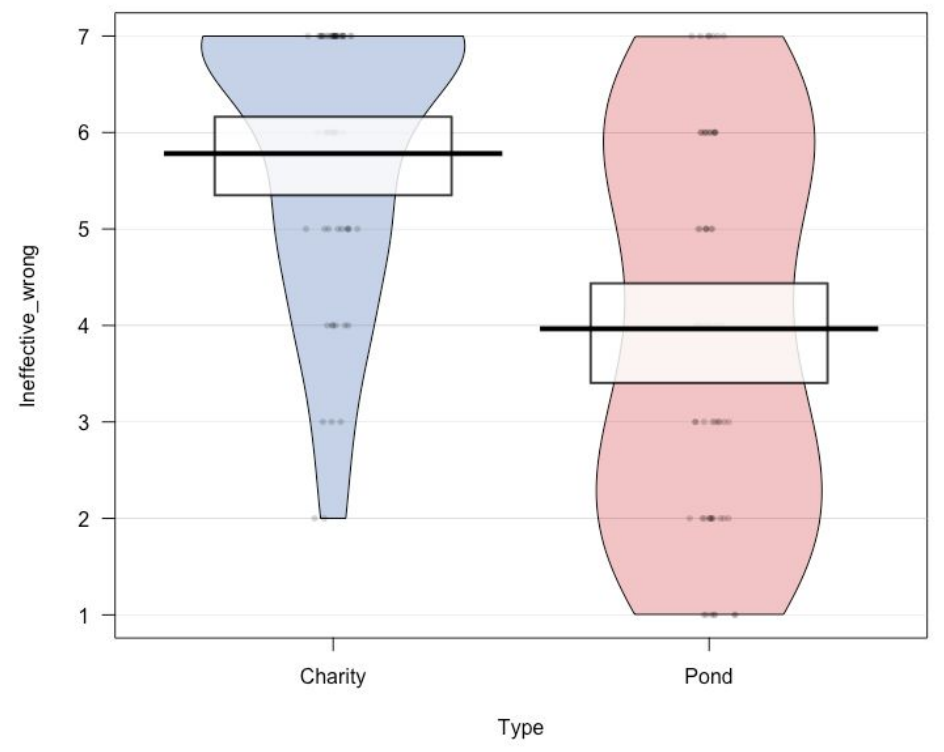

Figure 1. Participants found it not wrong to donate ineffectively conditional on donating. They found it more wrong to help the drowning children ineffectively conditional on helping. $(1=$ Extremely wrong, 7 = Not wrong at all.)

\section{Pilot 2: Distance}

Why, then, do people find it more wrong to help the drowning children ineffectively, than to donate ineffectively? Given the strong correlations between perceived wrongness to help/donate ineffectively, and perceived wrongness to not help/donate at all, it is natural to look at the literature on factors influencing perceived wrongness to not help/donate at all. One such factor is physical proximity: perceived wrongness of failing to help/donate increases with physical proximity (Musen \& Greene, 2011). In study $2(\mathrm{~N}=55$, between subjects design), we therefore manipulated the distance to the beneficiary of the donation while keeping everything else constant. Participants in the distant condition were again told to imagine that they had received charity leaflets in the mail, whereas participants in the proximate condition were told to imagine that they were tourists in Africa when arriving at an area affected by a lethal disease. There was also another difference compared with pilot 1: we stated the absolute numbers of people whom they could save if they choose the effective and ineffective options (ten children vs one child) rather than just the relative difference (ten times more children) like we had in Pilot 1.

Interestingly, we didn't find any effect of distance: the perceived wrongness of donating ineffectively was the same in the two cases. Participants found it more wrong to donate ineffectively than they did in Pilot 1, however: a difference which we attribute to the introduction of absolute numbers (see Appendix). Finally, note that participants in the proximate condition did find it more wrong not to help at all, in line with Musen and Greene's findings. Thus this means that in this study, perceived wrongness of donating ineffectively and perceived wrongness of not donating all came apart more than in Pilot 1. 


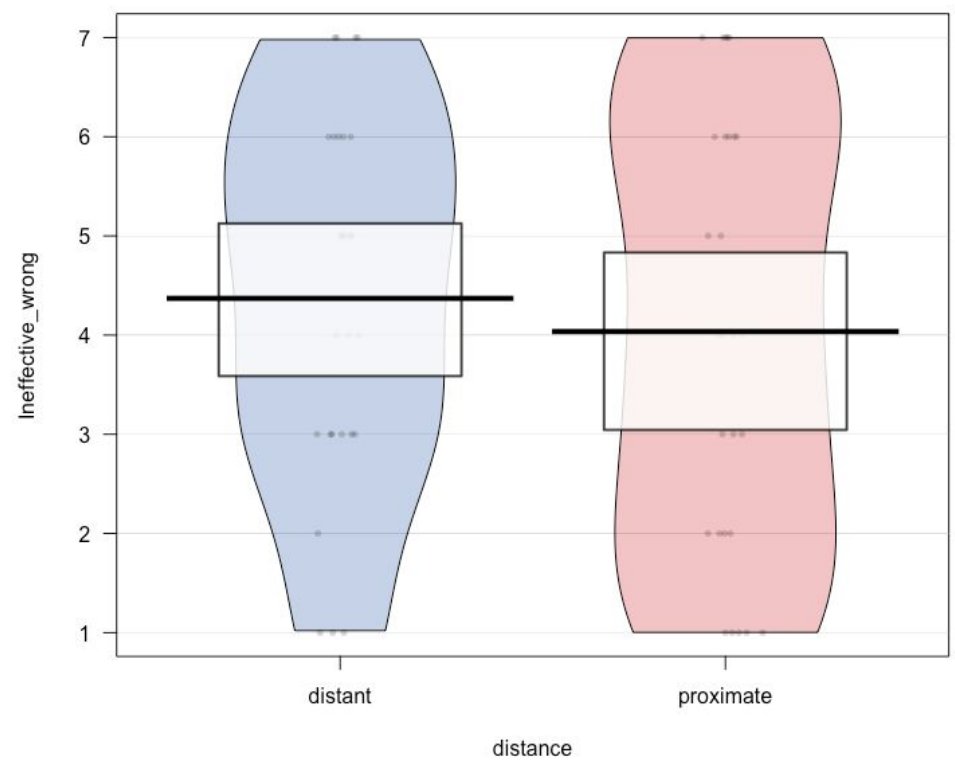

Figure 2. Distance didn't make a difference to perceived wrongness of donating/helping ineffectively if everything else was held constant

\section{Pilot 3: Number of helpers and urgency}

In Pilot $3(\mathrm{~N}=144,2 \times 2$ between subjects design), we studied two other hypotheses of why people find it less wrong to help ineffectively in the drowning child case than in the charity case: urgency (there is a more urgent need of help in the drowning child case) and whether you are alone or not (it is more plausible to think that you are the only one who can help in the drowning child case than in the charity case). Participants were again told to imagine that they are travelling in Africa, either by themselves (alone condition) or with others (other helpers condition), when they encountered an area where a lethal disease threatened to kill children within the next hour (high urgency condition) or year (low urgency condition).

We found one main effect: participants who were told to imagine they are the only ones who can help found it significantly more wrong to help ineffectively than participants who were told that there were others who also could help. One interpretation is that this is because they find it clearer that they are to blame for people dying if they help ineffectively, if there is no other helper there. We also found that this effect was stronger in the high urgency condition. We found no main effect from the urgency manipulation, however. We also did not find any clear patterns regarding how wrong it is not not to help at all across the four conditions (see Appendix). 


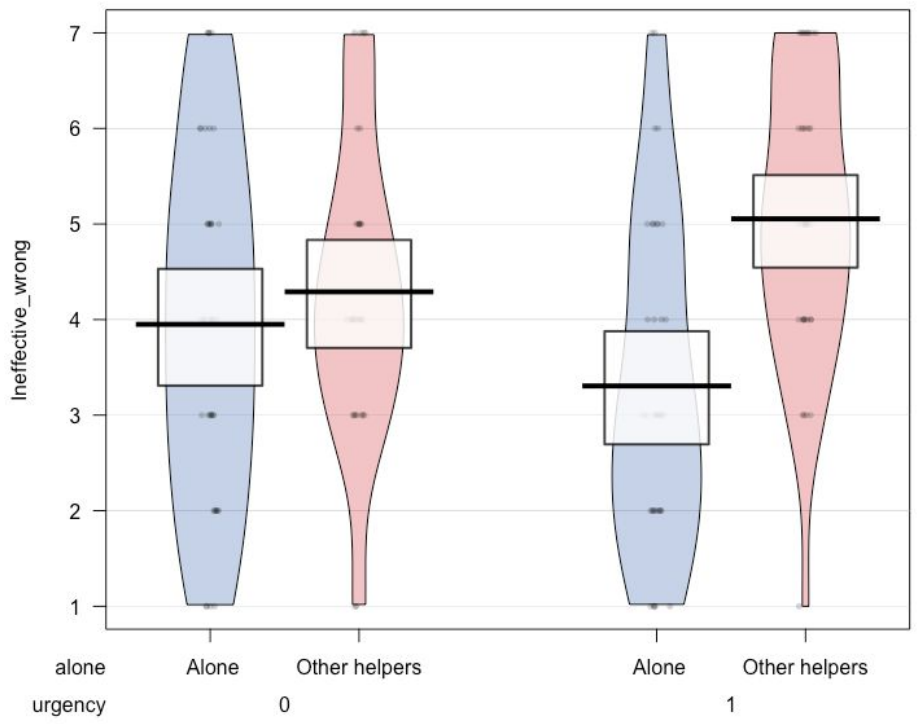

Figure 3. People considered it more wrong to help ineffectively if they assumed they were the only ones who would help than if they thought others would help too. This effect was stronger when the situation was urgent compared to when it was not urgent.

\section{Pilot 4: Wasteful interventions vs. less tractable problems}

In this study ( $\mathrm{N}=86$, between subjects design), we aimed to explore whether people are sensitive to the explanation of why one charity is less effective. We manipulated whether the ineffective charity was less effective because it focused on a less tractable problem or because it relied on a less effective (wasteful) intervention. More specifically, in the problems condition, we told participants that the effective charity was more effective because it focused on an area that had more children than the ineffective charity. In the interventions condition, we told participants that the effective charity used a more effective medicine than the ineffective charity. In both conditions the charities were said to focus on different areas.

The results were clear: participants found the ineffective option significantly more wrong when it was due to an ineffective intervention compared to when it was due to the problem being less tractable (Figure 4). One interpretation is that participants consider all problems worth solving, but don't consider all interventions worth supporting. Ineffective interventions are seen as wasteful because there would be a more effective way of solving the same problem. By contrast, focusing on an intractable problem is not seen as wasteful even if there would be other, more tractable problems to focus on. 


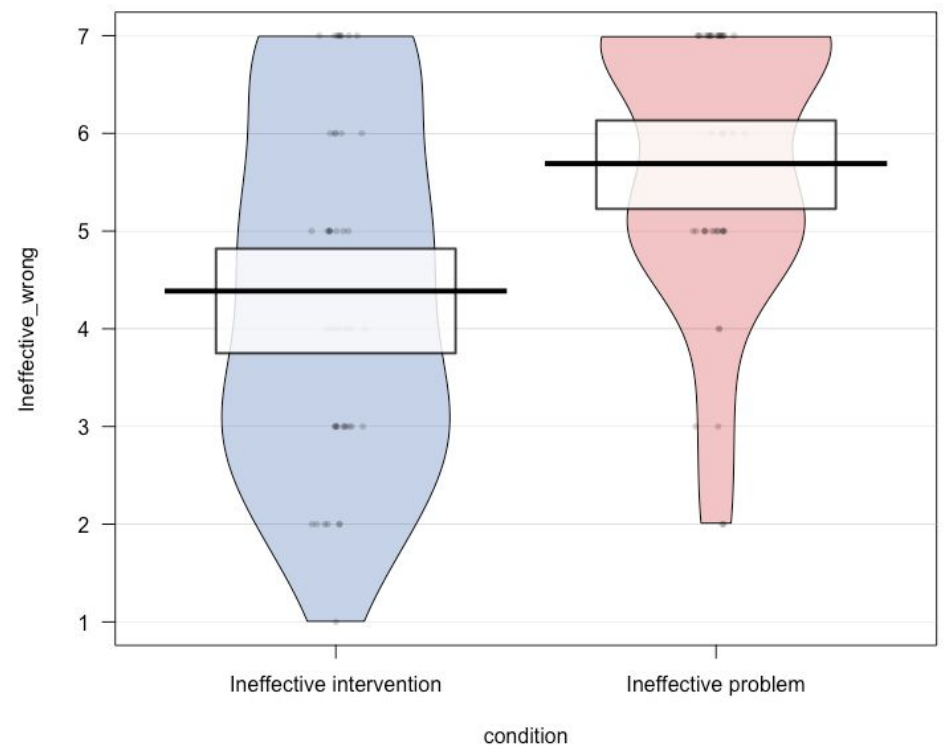

Figure 4. Participants considered it more wrong to donate to a charity that uses an ineffective intervention (meaning that it is wasteful) compared to a charity that focuses on a problem that is difficult to solve (meaning that it is not wasteful).

\section{Pilot 5: Pareto dominant charity}

In all studies so far, we had always compared two different groups of beneficiaries. Thus the more effective charity always helped different people than the less effective charity. This seems appropriate, since in the real world, effective charities typically don't help the same beneficiaries as less effective charities.

In this study ( $\mathrm{N}=80$, between subjects design) we wanted to test whether people find it more obligatory to choose the effective charity when it Pareto-dominates the less effective charity: that is, if the effective charity makes some people better off, and no one worse off. Again, we stated the absolute numbers of lives the participants could save if they choose the effective and ineffective charity, respectively (10 lives vs 1 life). We had three conditions: one where the effective charity helped a different group than the ineffective charity (Separate; thus no Pareto domination), one where the effective charity helped a superset of the ineffective charity's set of beneficiaries (Super), and one where both charities helped the same beneficiaries, but the effective charity helped them more (Intra). We found that participants found it quite wrong to donate ineffectively in the two Pareto domination conditions - and significantly more so than in Separate (see Figure 5). In contrast, there was no effect of Pareto dominance on the perceived obligation to donate at all. In the Pareto dominant conditions, people had the Pummerian intuition that it is more wrong not to donate effectively, than not to donate at all.

What explains these results? One explanation of the difference between Pareto dominated ineffective options and ineffective options which are not Pareto dominated is that in the latter case people have to deprioritize a certain group of people. They may not like this, e.g., because they find that one cannot 
compare the values of separate sets of human lives. But another explanation, which is likely at least partly correct, is that the observed difference is due to the wastefulness factor from Pilot 4 . The Pareto dominated charities in Pilot 5 are wasteful (in the sense that there is a better way of helping the same beneficiaries), unlike the ineffective charity which is not Pareto dominated (in Separate). Since we observed an effect from differences in wastefulness in Pilot 4, this should explain at least part of the difference between Superset and Intra, on the one hand, and Separate, on the other hand.

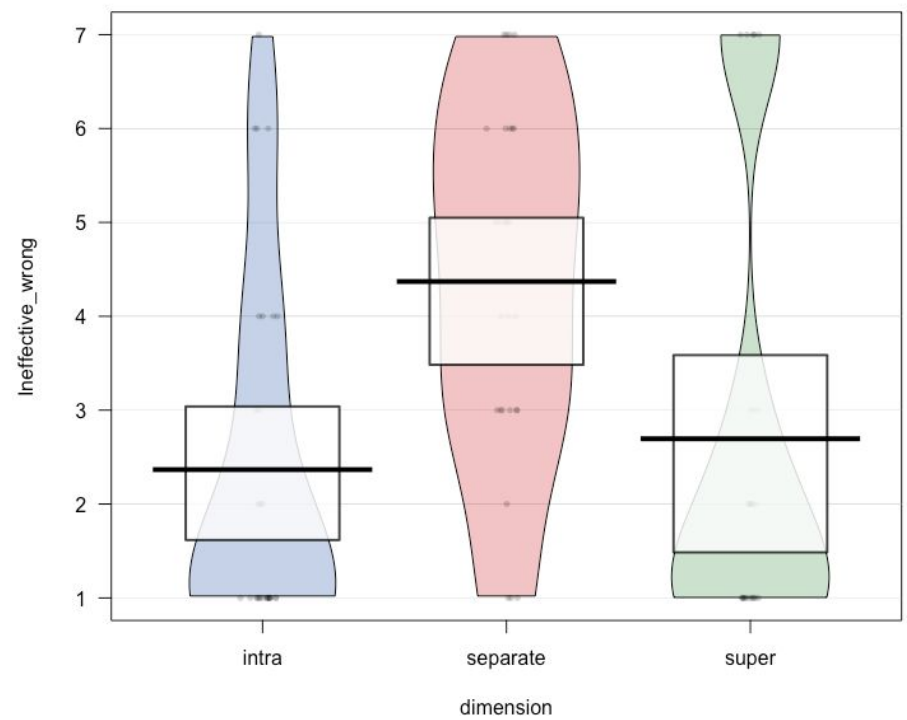

Figure 5. Participants perceived it as very wrong to donate to charities that helped only a subset of a group and to charities that helped the same individuals to a lesser extent compared to charities that Pareto-dominated these charities.

\section{Discussion}

We have found that in normal charity contexts, people don't find it wrong to donate ineffectively unless the intervention is suboptimal (i.e., wasteful), or unless there is no one else who can help. Why is that?

We have two main explanations, which are not necessarily mutually exclusive:

\section{Unwillingness to deprioritize any problem}

People might think that all problems deserve to be solved (for reasons of fairness), irrespective of how much progress one can make by focusing on them. And that it therefore isn't wrong to focus on a problem with lower marginal expected value. This may partly be driven by the fact that people find charities which focus on different problems incomparable, meaning that it would not be possible to say that one is better than the other. For example, people disagree that saving one life is less valuable than saving two lives (cf. the literature on sacred/protected values and taboo trade-offs; Baron \& Spranca, 1997; Tetlock, 2003). 
An open question for this hypothesis is why they think it is more wrong to donate ineffectively if they are alone. They may feel more responsible when they are the only person who can help, and therefore more focused on outcomes (cf. how omission bias is reduced when responsibility is increased; Haidt \& Baron, 1996). If other people could help as well, it becomes less clear whether fewer people were saved as a result of you choosing an ineffective option. Potentially the increased responsibility makes them more willing to overcome taboo trade-offs.

(Note that this hypothesis may also explain why people split their donations.)

\section{Incorrect model of how communal problem-solving works}

On this hypothesis, people have a naive view of how global problem-solving works, thinking that different actors are more coordinated than they actually are. Donors are thinking of themselves effectively as part of a vast community of donors, including besides other individuals also governments and large foundations. They think that together, this community can and should tackle all of the world's problems. This means that focusing on solving an intractable problem is not necessarily wrong, since all problems need to be addressed eventually. According to this hypothesis, people's views about their marginal impact is incorrect: they falsely believe that it is about as large regardless of what problem they focus on. (A reason against this hypothesis is that we usually made clear to the participants that their marginal impact would be greater if they donated to the effective charity. However, it is possible that participants didn't understand this fully. Future studies could measure their beliefs about their marginal impact.)

This hypothesis says that people are thinking of this large community as analogous to a (large) group of friends cleaning out their house at the end of their stay. Some rooms are easier to clean than others - e.g., it may take longer time to clean the kitchen than the living room. However, since you are all in this together, it is not wrong to start cleaning the kitchen - eventually, the whole house needs to be cleaned! By contrast, using an ineffective (wasteful) cleaning method is wrong, since it will delay getting the whole house clean (but not as wrong as not helping at all).

If people are the only ones helping, however, they are not thinking in these terms, but realize that there is no way that they are going to be able to solve all of the problems that they are confronted with. Instead, they realize that they need to prioritize, and will find it wrong not to do so.

\section{Appendix}

\section{Pilot 1}

\section{Charity condition}

One morning you receive two leaflets of charities in your mail. Both charities work to prevent Malaria in children in different African towns. Neither charity is wasteful, and the staff have the same salaries. However, because there are more children in one of the towns, donations to charity A saves ten times more children than donations to charity B does. You don't know any of these children. 
Suppose that you've decided to donate. Given that you've decided to donate, would it be wrong to donate to charity B, which would help ten times fewer children than it would to donate to charity A? [1 Extremely wrong - 7 Not wrong at all]

Would it be wrong not to donate at all in this case? [1 Extremely wrong - 7 Not wrong at all]

\section{Pond condition}

One morning you are walking alone through the woods and suddenly notice two ponds in front of you. In both ponds there are children about to drown. There is one boat in each pond which you can use to save the children, but you only have time to save children in one of the ponds. However, because there are more children in one of the ponds, taking boat A saves ten times as many children as taking boat B. You don't know any of these children.

Suppose that you've decided to help. Given that you've decided to help, would it be wrong to take boat B, which would help ten times fewer children than it would to take boat A? [1 Extremely wrong - 7 Not wrong at all]

Would it be wrong not to donate at all in this case? [1 Extremely wrong - 7 Not wrong at all]

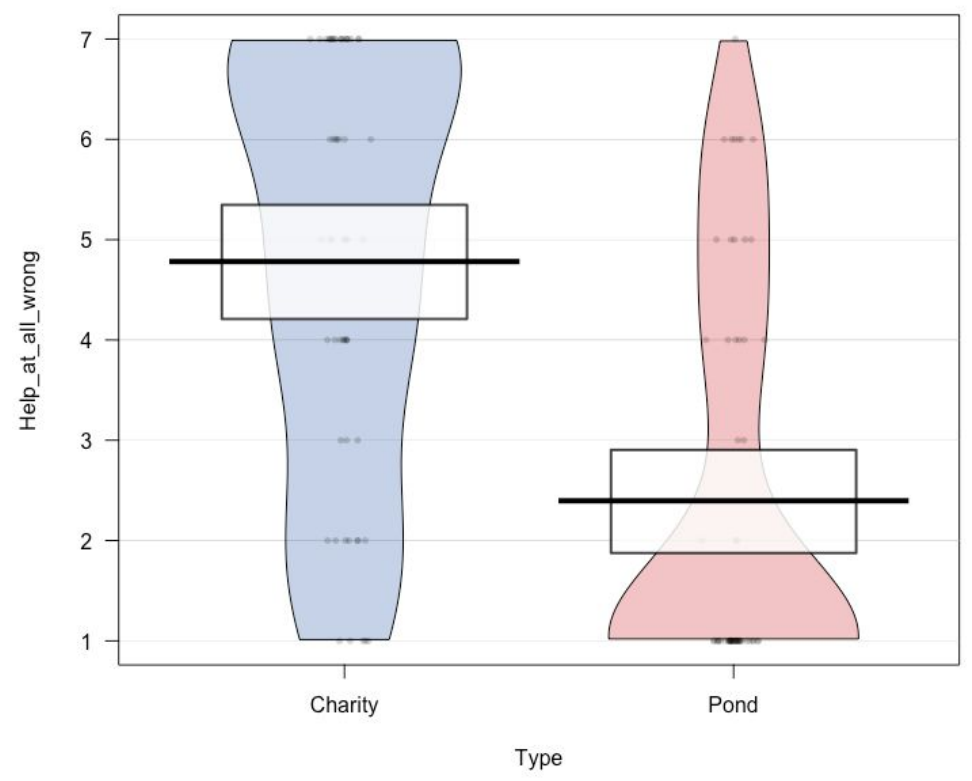

Figure 6. Participants considered it more wrong to not help at all in the drowning children case compared to not donating at all.

\section{Pilot 2}

\section{Proximate}

Imagine the following: 
You are a tourist in a remote area in Africa. When travelling, you arrive at an area where there is an outbreak of a lethal disease. While adults are safe (including yourself), many children are affected, and you see children who are dying painfully all around you. You have $\$ 500$ which you can use to buy medicine to help the children in one of the towns.

There are two towns that are affected: town A and town B. You only have time to help children in one of the towns. Since more children are affected in town A, you will save ten children if you go to town A, whereas you will save only one save child if you go to town B.

Consider the following options:

Option A: If you choose to go to town A, you will be able to save ten children in town A. Option B: If you choose to go to town B, you will be able to save one child in town B.

\section{Distant}

Imagine the following:

Watching the news, you learn about the outbreak of a lethal disease in towns of a remote area in Africa. While adults are safe, many children are affected, and you see children who are dying painfully in the news. You have $\$ 500$ which you can use to donate to help the children. You know of two charities that are both proven not to be wasteful (e.g., the staff have the same salaries).

The two charities focus on distributing medicines in different towns: charity A distributes medicine in town A and charity B distributes medicine in town B. Since more children are affected in town A, donating to charity A will save ten children, whereas donating to charity B will save only one child.

Consider the following options:

Option A: If you choose to donate to charity A, you will be able to save ten children in town A. Option B: If you choose to go to charity B, you will be able to save one child in town B.

\section{DVs}

Suppose that you have decided to help [donate]. Would it be wrong to choose Option B instead of Option A? [1 Extremely wrong - 7 Not wrong at all]

Would it be wrong not to help [donate] at all in this case? [1 Extremely wrong - 7 Not wrong at all] 


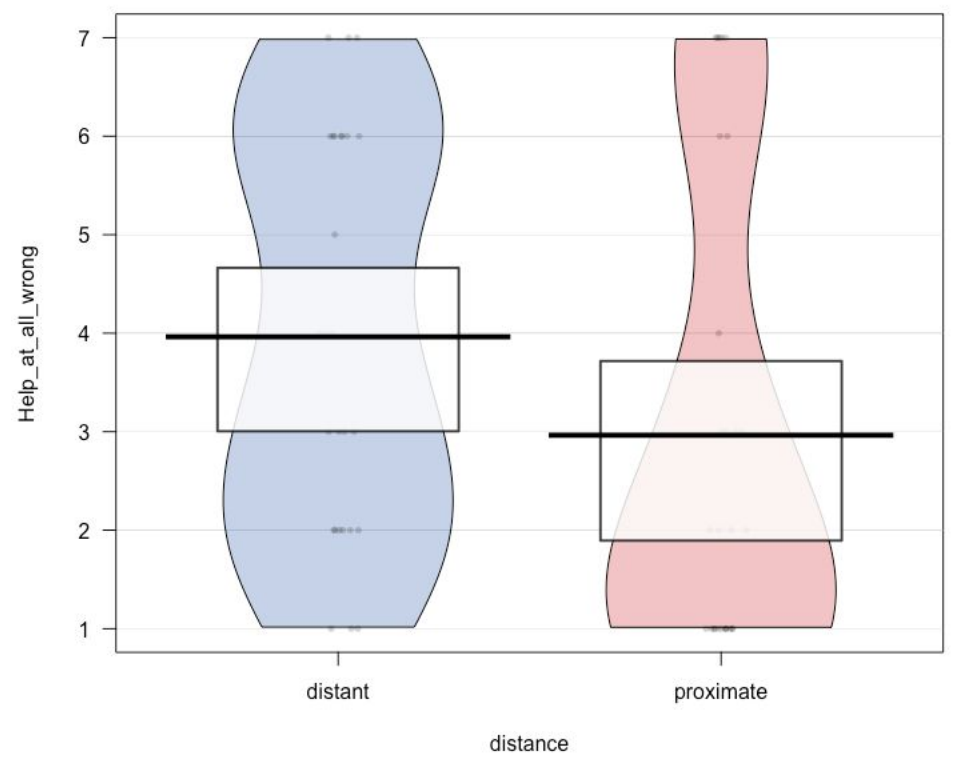

Figure 7. Participants considered it more wrong to not help at all in the proximate case compared to not donating at all in the distant case.

\section{Pilot 3}

You are a tourist in a remote area in Africa. When travelling by yourself [with a large group of tourists], you arrive at a remote area where there is an outbreak of a lethal disease. While adults are safe (including yourself), many children in this remote area are affected. The disease will kill the affected children within the next years [hour] unless they are being treated with medicine.

You have $\$ 500$ which you can use to buy medicine to help the children. There is no one else who is helping the children: you are the only one. [There are many other other people who are helping the children: you are not the only one.]

There are two types of medicines that cure the children. Medicine A only helps children with blood type A, and medicine B only helps children with blood type B. Half of the affected children have blood type A, and half have blood type B. Both medicines are the most effective medicines for the respective blood type groups. However, for bio-medical reasons, it is more difficult, and therefore ten times more expensive, to develop a medicine for children with blood type B than to develop a medicine for children with blood type A. Therefore, with the $\$ 500$ you have available you can help ten times more children if you buy medicine A instead of medicine B.

DVs

Suppose you decide to help. Would it be wrong to buy medicine B, which will help ten times fewer children than if you bought medicine A instead? [1 Extremely wrong - 7 Not wrong at all] 
Suppose you have decided to help. Which medicine would you buy? [1 Definitely A - 4 flip a coin to decide - 7 Definitely B]

Would it be wrong not to help at all in this case? [1 Extremely wrong - 7 Not wrong at all]

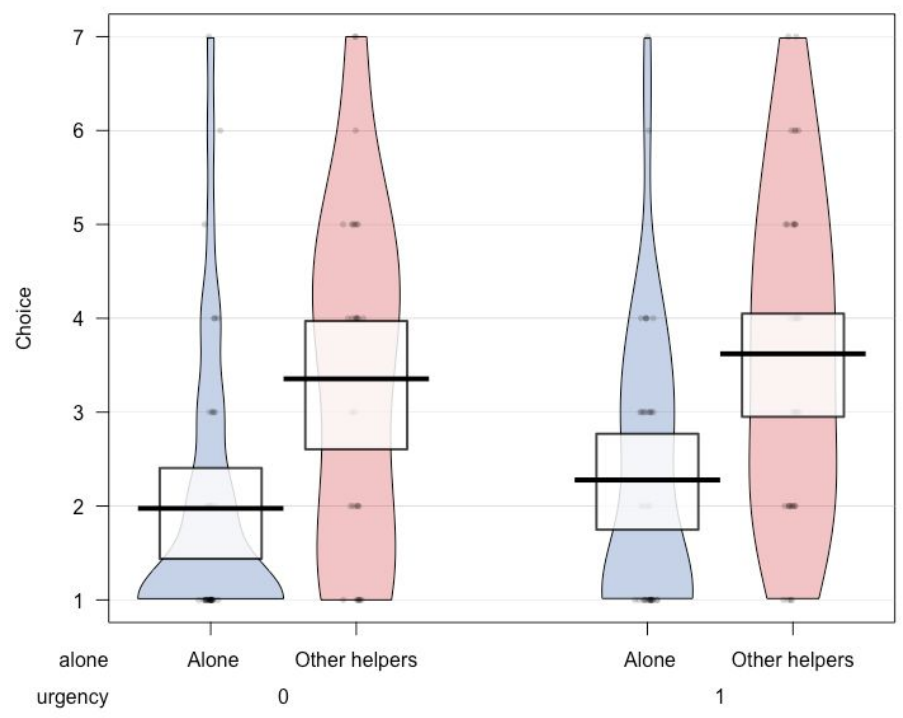

Figure 8. Participants were more likely to choose the effective option when alone, and tended to flip a coin whether to help effectively or ineffectively when they assumed others would help too.

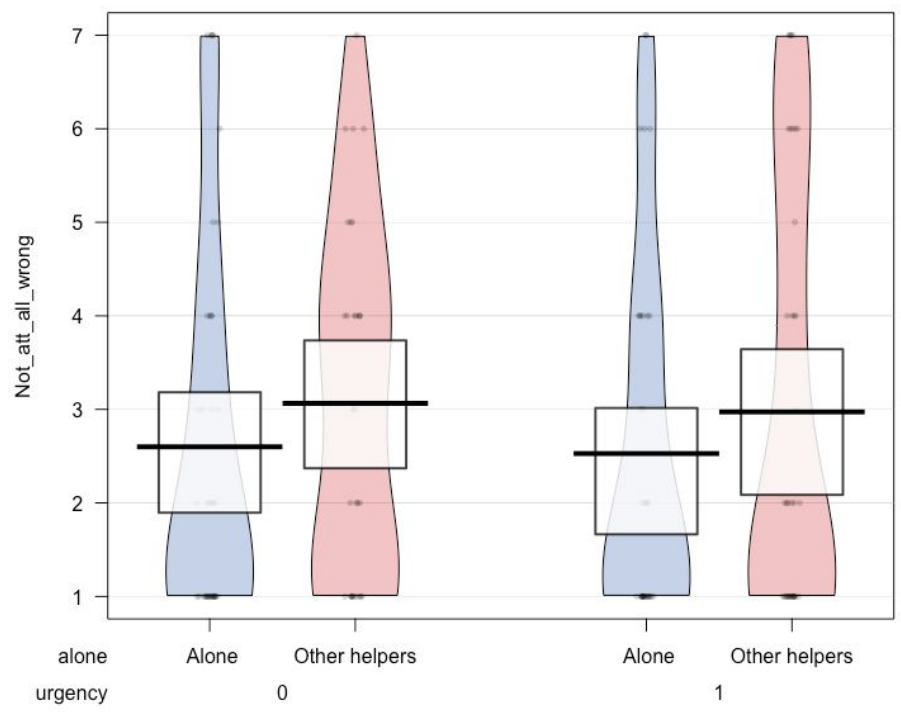

Figure 9. Participants considered not helping at all equally wrong in all conditions 


\section{Pilot 4}

\section{Ineffective problem}

Imagine the following:

One morning you receive two leaflets of charities in your mail. Both charities work to save the lives of children who are at risk of a dangerous and deadly disease in different areas of Africa. Neither charity is wasteful, and the staff have the same salaries. Both charities urgently need donations to the same extent.

Charity A works to save children in African area A.

Charity B works to save children in African area B.

However, because there are more children in area A, your donation to Charity A will save ten times more children than the same donation to Charity B.

\section{Ineffective intervention}

Imagine the following:

One morning you receive two leaflets of charities in your mail. Both charities work to save the lives of children who are at risk of a dangerous and deadly disease in different areas of Africa. Neither charity is wasteful, and the staff have the same salaries. Both charities urgently need donations to the same extent.

Charity A works to save children in African area A.

Charity B works to save children in African area B.

However, because Charity A uses a more effective type of medication, your donation to Charity A will save ten times more children than the same donation to Charity B.

\section{DVs}

Suppose you have decided to donate to one of these two charities. Would it be wrong to donate to Charity B instead of Charity A? [1 Extremely wrong - 7 Not wrong at all]

Suppose you have decided to donate to one of these two charities. Which charity would you donate to? [1 Definitely A - 4 flip a coin to decide - 7 Definitely B]

Would it be wrong not to donate at all in this case? [1 Extremely wrong - 7 Not wrong at all] 


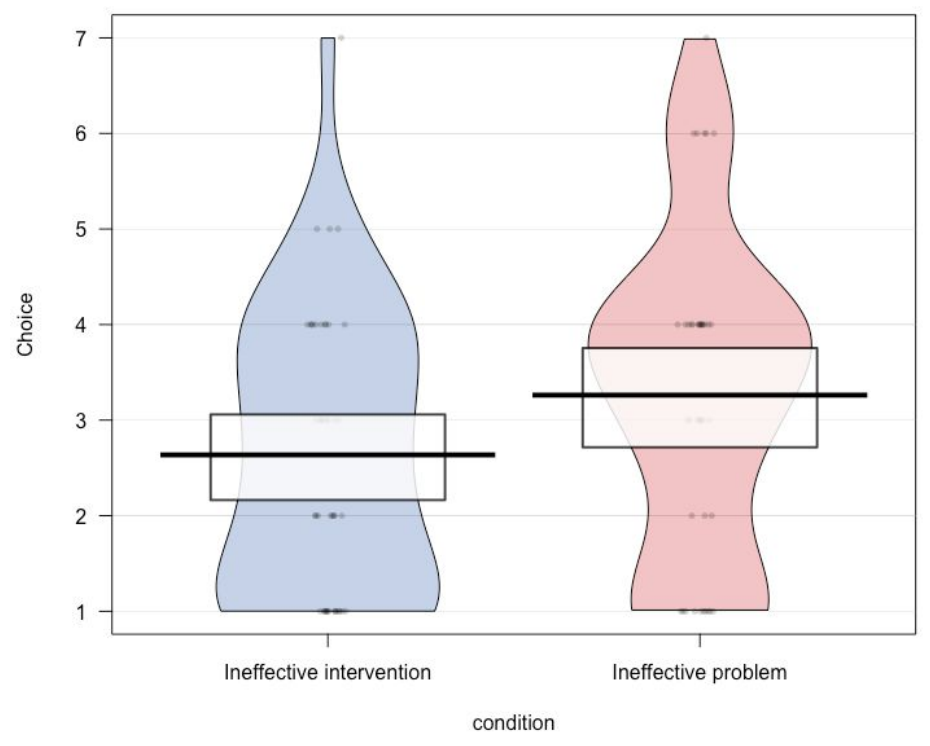

Figure 10. Most participants flipped a coin to choose between the effective and ineffective problem charities. In contrast, participants were more likely to choose the charity with the effective compared to the ineffective intervention.

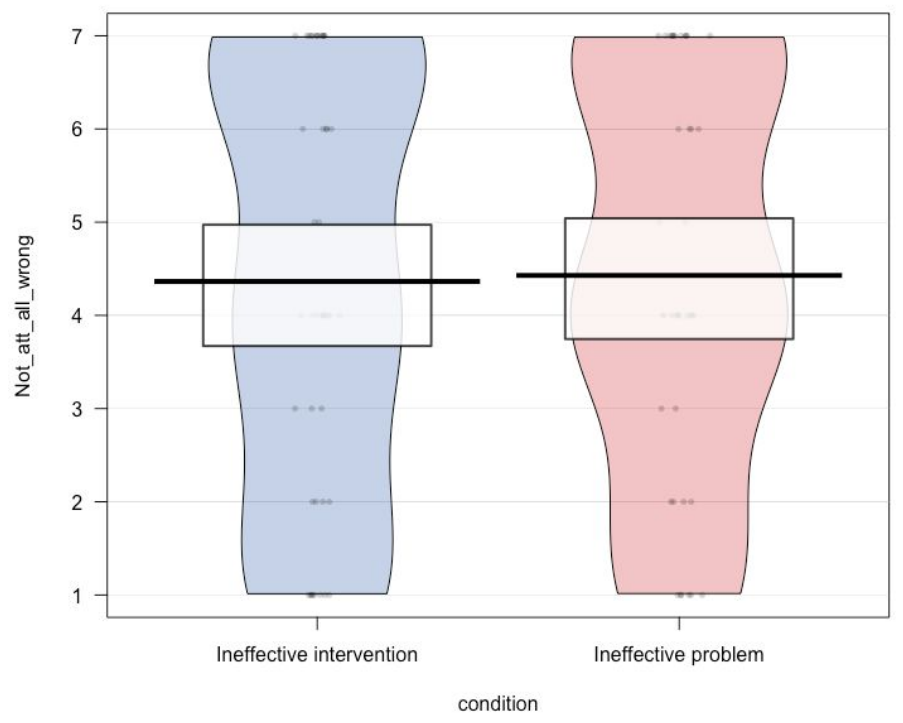

Figure 11. Participants considered it equally permissible to not donate at all.

\section{Pilot 5}

\section{Separate}

Imagine the following: 
Watching the news, you learn about the outbreak of a lethal disease in towns of a remote area in Africa. While adults are safe, many children are affected, and you see children who are dying painfully in the news. You have $\$ 500$ which you can use to donate to help the children. You know of two charities that are both proven not to be wasteful (e.g., the staff have the same salaries).

The two charities focus on distributing medicines in different towns: charity A distributes medicine in town A and charity B distributes medicine in town B. Since more children are affected in town A, donating to charity A will save ten children, whereas donating to charity B will save only one child.

Consider the following options:

Option A: If you choose to donate to charity A, you will be able to save ten children in town A. Option B: If you choose to go to charity B, you will be able to save one child in town B.

\section{Super}

Imagine the following:

Watching the news, you learn about the outbreak of a lethal disease in towns of a remote area in Africa. While adults are safe, many children are affected, and you see children who are dying painfully in the news. You have $\$ 500$ which you can use to donate to help the children. You know of two charities that are both proven not to be wasteful (e.g., the staff have the same salaries).

The two charities focus on distributing different medicines in the same town: charity A distributes medicine A and charity B distributes medicine B. The medicines are both equally good at curing the disease, but medicine A is ten times cheaper than medicine B. Since medicine A is cheaper than medicine B, donating to charity A will save ten children, whereas donating to charity B will save only one of those ten children.

Consider the following options:

Option A: If you choose to donate to charity A, you will be able to save ten children.

Option B: If you choose to donate to charity B, you will be able to save one of those ten children.

\section{Intra}

Imagine the following:

Watching the news, you learn about the outbreak of a lethal disease in towns of a remote area in Africa. While adults are safe, many children are affected, and you see children who are dying painfully in the news. You have $\$ 500$ which you can use to donate to help the children. You know of two charities that are both proven not to be wasteful (e.g., the staff have the same salaries).

The two charities focus on distributing different medicines in the same town: charity A distributes medicine A and charity B distributes medicine B. The medicines cost the same. However, medicine A 
cures the disease permanently, whereas medicine B only cures the children for five years, at which point they will certainly die (there is no chance of recovery).

Consider the following options:

Option A: If you choose to donate to charity A, you will be able to cure ten children permanently. Option B: If you choose to donate to charity B, you will be able to cure ten children for five years.

\section{DVs}

Suppose that you have decided to help [donate]. Would it be wrong to choose Option B instead of Option A? [1 Extremely wrong - 7 Not wrong at all]

Would it be wrong not to help [donate] at all in this case? [1 Extremely wrong - 7 Not wrong at all]

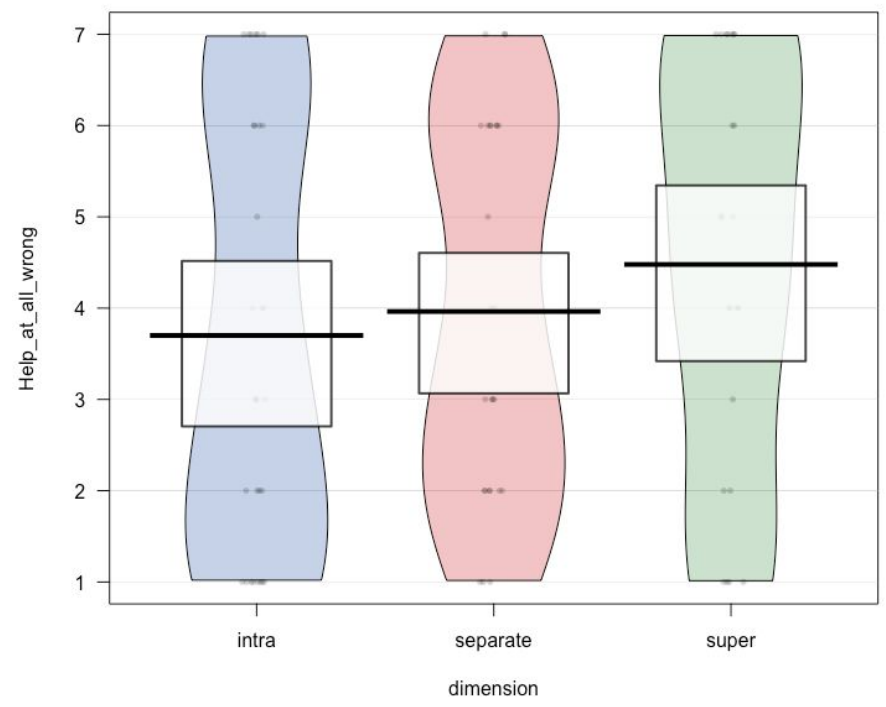

Figure 12. Participants considered it roughly equally permissible to not donate at all in all conditions.

\section{References}

Baron, J., \& Spranca, M. (1997). Protected values. Organizational behavior and human decision processes, 70(1), 1-16.

Berman, J. Z., Barasch, A., Levine, E. E., \& Small, D. A. (2018). Impediments to Effective Altruism: The Role of Subjective Preferences in Charitable Giving. Psychological science, 29(5), 834-844. 
Haidt, J., \& Baron, J. (1996). Social roles and the moral judgement of acts and omissions. European Journal of Social Psychology, 26(2), 201-218.

Parfit, D. (1982). Future generations: Further problems. Philosophy \& public affairs, 113-172.

Pummer, T. (2016). Whether and where to give. Philosophy \& Public Affairs, 44

McMahan, J. (2018). Doing Good and Doing the Best, in Paul Woodruff, ed., Philanthropy and Philosophy: Putting Theory Into Practice. Oxford University Press.

Musen, J. \& Greene, J. (2011). The Moral Psychology of Obligations to Help Those in Need. Unpublished Dissertation.

Nagel, J., \& Waldmann, M. R. (2013). Deconfounding distance effects in judgments of moral obligation. Journal of Experimental Psychology: Learning, Memory, and Cognition, 39(1), 237.

Tetlock, P. E., Kristel, O. V., Elson, S. B., Green, M. C., \& Lerner, J. S. (2000). The psychology of the unthinkable: taboo trade-offs, forbidden base rates, and heretical counterfactuals. Journal of personality and social psychology, 78(5), 853 .

Woodruff, P. (Ed.). (2018). The Ethics of Giving: Philosophers' Perspectives on Philanthropy. Oxford University Press. 